\title{
Metabolic factors that affect health-related quality of life in type 2 diabetes patients: a multivariate regression analysis
}

This article was published in the following Dove Press journal: Diabetes, Metabolic Syndrome and Obesity: Targets and Therapy

\author{
Tania Dehesh' \\ Paria Dehesh ${ }^{2}$ \\ Mohammad Hossein Gozashti ${ }^{3}$ \\ 'Department of Biostatistics and \\ Epidemiology, School of Public Health, \\ Kerman University of Medical Sciences, \\ Kerman, Iran; ${ }^{2}$ Graduated of Veterinary \\ Medicine Faculty, Shahid Bahonar \\ University of Kerman, Kerman, Iran; \\ ${ }^{3}$ Department of Endocrinology, Kerman \\ University of Medical Sciences, Kerman, \\ Iran
}

Correspondence: Paria Dehesh Graduated of Veterinary Medicine Faculty, Shahid Bahonar University of Kerman, Haft Bagh Alavi, Kerman 7617647633, Iran

Tel $+98343 \quad 1325065$

Fax +98343137378

Email paria_dehesh@yahoo.com
Purpose: In the past few decades, an increase in the life span of the population has caused more people to experience chronic diseases, such as type 2 diabetes. Since chronic diseases influence the whole life of patients and do not have a specific remedy, improving their healthrelated quality of life (HRQoL) becomes more important. The aim of the present study was to investigate the metabolic variables that influenced HRQoL questionnaire scores most significantly among patients with type 2 diabetes.

Patients and methods: The population of this cross-sectional study included 163 patients with type 2 diabetes and 214 healthy people who were asked to complete the HRQoL questionnaire, and their metabolic blood variables were recorded simultaneously. The effects of metabolic variables and some other demographic ones on two main scales of HRQoL, Mental Component Summary (MCS) and Physical Component Summary (PCS), were evaluated using multivariate regression.

Results: Multivariate regression analysis showed that PCS score was most negatively influenced by cigarette smoking $(P=0.009, \quad \beta-15.761)$, maximum blood pressure $(P=0.008, \beta=-0.108)$, minimum blood pressure $(P=0.009, \beta=-0.039)$, low-density lipoprotein cholesterol $(P=0.008, \beta=-0.721)$, cholesterol $(P=0.006, \beta=-0.648)$, HbA1c $(P=0.004, \quad \beta=-0.878)$, FBS $(p=0.006, \quad \beta=-0.769)$, and body mass index (BMI) $(P=0.034, \beta=-0.287)$. The MCS score was influenced positively by smoking cigarettes $(P=0.041, \beta=13.032)$, gender $(P=0.018, \beta=15.633)$, and BMI $(P=0.048, \beta=-0.088)$. Men had a higher MCS score compared to women.

Conclusion: The HRQoL questionnaire (as a concept of health) score could be improved by controlling the variation of some metabolic variables in patients with type 2 diabetes. Some metabolic variables could be the main causes of a decrease in physical and mental HRQoL among patients with type 2 diabetes.

Keywords: quality of life, SF-36 questionnaire, metabolic variables

\section{Introduction}

Type 2 diabetes is one of the most serious chronic diseases with complex complications and treatment, and the majority of patients have depression symptoms. ${ }^{1}$ Type 2 diabetes has achieved epidemic levels in most countries and epidemiologic studies have indicated that without efficient prevention and control programs, its prevalence will continue to rise globally. ${ }^{2}$ It is estimated that there were 366 million people with diabetes in 2011 , and that will increase to more than 552 million in $2030 .^{3}$ In Iran, as in other developing countries, the number of people with type 2 diabetes is increasing due to the change in lifestyle. The prevalence of type 2 diabetes in Iran was $5.5 \%$ in 2008 . $^{4}$ 
Patients with diabetes have to manage their level of blood glucose by controlling nutrition and using difficult treatment. Living with a controlled daily schedule leads to chronic stress among these patients. ${ }^{5}$

Health-related quality of life (HRQoL) is defined as a multifactorial concept that shows physical, mental, and social functioning in a person's life that may be affected by disease. ${ }^{6}$ Researchers have shown that, physicians' evaluation of health may not be in accordance with patients' understanding of health. ${ }^{7}$

According to the WHO, the conventional concept of health, which means the absence of disease, should be reviewed. ${ }^{8}$ Therefore, HRQoL can be considered as a main health outcome and represents the result of therapeutic interventions in the best manner. ${ }^{9}$

Specific diet and medication dependency in diabetic patients ${ }^{10,11}$ decrease their HRQoL level. ${ }^{12}$ Previous studies have confirmed that the HRQoL of patients with type 2 diabetes is lower than the HRQoL of general people. ${ }^{6,13,14}$ A higher body mass index (BMI) (BMI $\left.\geq 30 \mathrm{~kg} / \mathrm{m}^{2}\right),{ }^{15-18}$ old age, ${ }^{19,20}$ gender (particularly women), and having hypertension as a concomitant disease ${ }^{9}$ could be the main causes of low HRQoL among patients with diabetes.

The HRQoL concept is usually evaluated with a special questionnaire. The Short Form (36) Health Survey (SF-36) is a famous questionnaire for evaluating HRQoL in different types of disease.

The SF-36 is a 36-item questionnaire consisting of eight domains, and also two summarized main scales which are called Physical Component Summary (PCS) and Mental Component Summary (MCS). ${ }^{21,22}$ These two scales categorize the HRQoL concept into two main concepts, physical and mental HRQoL. Using these two scales instead of eight domain scores leads to the simplest analysis and interpretation of the HRQoL concept. Many studies have shown the role of HRQoL in the life of patients with type 2 diabetes, but the relation between HRQoL (as a concept of health) and metabolic variables (as clinical measurements) has rarely been reported. The aim of this study was to first compare the HRQoL score between patients with type 2 diabetes and healthy people, and second, to determine the effect of metabolic variables and some demographic factors on PCS and MCS scales of patients with type 2 diabetes using multivariate regression.

\section{Materials and methods}

In total, 163 patients with type 2 diabetes were recruited from May to October 2018 (143 women and 20 men).
These patients were referred to Besat Laboratory for blood tests by an endocrinologist. Besat laboratory is the main laboratory for diabetes in Kerman (southern Iran). Participants under the age of 18 and pregnant women, as well as patients with other chronic diseases (type 1 diabetes, not having severe kidney disorders) were excluded from the study (eight patients). For comparison, 214 healthy people (147 women and 67 men), with no chronic diseases for at least 1 year, who had been coming to Besat laboratory for annual check-ups, were enrolled. Some of them may have used drugs for enjoyment (like a habit), but they did not have type 2 diabetes or any other chronic disease. The participants of this study completed informed consent forms before enrollment. They were asked to answer the SF-36 questionnaire in a quiet room and their minimum and maximum blood pressure (BP) was measured by a skilled nurse. BP was measured using a BP cuff in a seated position twice (first, on the blood test day and the second on the next day, when they came in to get their test result). The average of two BP measurements was recorded as BP value. They also answered questions about their personal characteristics that may have an effect on their HRQoL, such as smoking status, use of drugs, BMI, and level of education. The demographic variables were also recorded. After a night of fasting, $5 \mathrm{~mL}$ blood sample was taken from each person. After the formation of the clot, the serum was separated from the blood sample, and serum FBS, TG, total cholesterol, high-density lipoprotein cholesterol (HDL-C) and low-density lipoprotein cholesterol (LDL-C) levels were measured by BS-300 MINDRAY (Shenzhen Mindray Bio-medical Electronics Co., China) by Roche kits (Germany). HbAlc was measured by Enzymatic method (Selectra, Iran). For quality control purpose, TruCal HDL/LDL, Lot: 326007 was used to calibrate the biochemical tests and TruLab N, P Lot: 11483 and TruLab Lipid, Lot: 10502 were applied to check the accuracy of biochemical tests. To control the quality of HbA1c tests, Control Serum, Lot: 304687 was used. The study was approved by the ethics committee of Kerman University of Medical Sciences (reference number: IR.KMU.REC.1397.174). This study was conducted in accordance with the Helsinki Declaration of 1964.

The SF-36 questionnaire was used as a health survey instrument in order to evaluate HRQoL of the patients in the study. This questionnaire has eight main domains, including: physical function (PF, ten items), role physical (RP, four items), role emotional (RE, three items), social function (SF, two items), bodily pain (BP, two items), mental health ( $\mathrm{MH}$, 
five items), vitality (VT, four items), and general health (GH, five items) perceptions, and two summary scales, PCS and MCS, which are produced by factor analysis of eight domain scores. In the second version, four domains, including PF, $\mathrm{RP}, \mathrm{BP}$, and GH are highly correlated with the physical component and contribute to scoring the PCS and also four domains, including $\mathrm{MH}, \mathrm{RE}, \mathrm{SF}$, and VT are highly correlated with the mental components which contribute to scoring the MCS measure. In fact, eight domains were summarized in two main scales. Each raw domain score has equal weight between 0-100 scores, and higher scores denote better health status in all dimensions. The SF-36 that was used in this study had previously been translated into Persian, and its reliability and validity have been defined in a previous study in Iran. ${ }^{21}$

Multivariate regression was used when the effect of some variables on more than one outcome variable was evaluated. Multivariate regression was used in order to assess the effect of some metabolic and demographic variables on MCS and PCS as a vector of outcomes. The Shapiro-Wilk test was used in order to check normality of continuous variables. The Wilks' Lambda and Pillai's trace were used for checking the overall test in multivariate multiple regression. For statistical assessment, SPSS version 20 was used. A value of $P<0.05$ was considered as statistically significant.

\section{Results}

The subject characteristics in patients and healthy groups are summarized in Table 1. As it was observed in both groups, the number of women were significantly more than men $(P<0.001)$. It may be due to the fact that women usually care more about their health. There were no significant differences between patient and healthy groups in smoking status ( $P=0.199$ ) and use of drugs ( $P=0.509)$, but in terms of education level, patient group had a significantly higher education level $(P<0.001)$. There was a statistically significant difference in mean of age between the two groups $(P<0.001)$. The patient group was older. The average BMI in the patient group was significantly higher than in the healthy group $(P=0.019)$

The comparison of BP and metabolic variables between patient and healthy groups is shown at the bottom of Table 1. As shown, there were statistically significant differences in the mean of maximum BP $(P=0.001)$, minimum BP $\quad(P<0.001), \quad$ HDL-C $\quad(P=0.004), \quad$ LDL-C $(p=0.012)$, and HbAlc $(P<0.001)$ between patient and healthy groups. The patient group had higher mean values for all of them. Triglycerides $(P=0.124)$ and total cholesterol $(P=0.426)$ were not significant between groups.
There were statistically significant differences in mean FBS and HbAlc between the two groups $(P<0.001)$, and the patient group had higher values in both compared to the healthy group.

Table 2 presents a comparison of HRQoL between type 2 diabetes patients and healthy people on eight domains and two summary scales of the SF-36 questionnaire. The scores of all domains showed the worse scores for type 2 patients, and $\mathrm{MH}(P=0.028)$, $\mathrm{PF}(P=0.039)$, and $\mathrm{GH}$ $(P=0.02)$ domain scores were significantly lower in the patient group. The MCS $(P<0.001)$ and PCS $(P=0.018)$ scores were also significant between them.

The effect of characteristics and metabolic variables on MCS and PCS scales of SF-36 questionnaire is presented in Table 3. The results of the multivariate regression analysis revealed that PCS was negatively influenced by cigarette smoking ( $P=0.009, \beta-15.761)$, BMI $(P=0.034, \beta-$ 0.287), maximum BP $(P=0.008, \beta=-0.108)$, minimum $\mathrm{BP}$ $(P=0.009, \beta=-0.039)$, LDL-C $(P=0.008, \beta=-0.721)$, Chol ( $P=0.006, \beta=0.648)$, HbAlc $(P=0.002, \beta=0.878)$, and FBS $(P=0.006, \beta=-0.769)$. The lower the educational level (diploma), the more significant the negative effect on PCS score ( $P=0.046, \beta=-10.328)$.

None of the metabolic variables had a significant effect on MCS score. The MCS score was influenced positively by smoking cigarettes $(P=0.041, \beta=13.032)$ and gender ( $P=0.018, \beta=15.633)$. Men had a higher MCS score compared to women. BMI had a significant negative effect on the MCS score $(P=0.048)$. The educational level had a significant effect on the MCS scale score. The higher the degree of education, the higher the MCS score.

\section{Discussion}

Today, assessment of quality of life is used as an important factor in the evaluation of health care outcomes. In the present research, the effects of metabolic variables that are reported routinely in blood tests on MCS and PCS scales have been studied. The pure effects of each metabolic variable on MCS and PCS scales revealed new insights regarding the relationship between clinical factors and HRQoL among patients with diabetes. In this study, most metabolic variables such as LDL-C, total cholesterol, and BP had a significant negative effect on PCS in type 2 diabetes patients. As another study showed similar negative associations between blood lipid index, BP, and HRQoL in patients with diabetes in Iran, ${ }^{23}$ and also in accordance with the result of Kontodimopoulos et al's work that confirmed the negative effect of high BP and higher lipidemia on GH 
Table I Subject characteristics of healthy people and type 2 diabetes patient groups

\begin{tabular}{|c|c|c|c|}
\hline & Healthy people $N=2$ I 4 & Type 2 diabetes patients $N=163$ & $P$-value \\
\hline \multicolumn{4}{|c|}{ Smoking, number (\%) } \\
\hline Yes & $15(7)$ & $18(11)$ & 0.199 \\
\hline No & 199(93) & $145(89)$ & \\
\hline \multicolumn{4}{|c|}{ Drug use, number (\%) } \\
\hline Yes & $4(1.9)$ & $5(3.1)$ & 0.509 \\
\hline No & $210(98.1)$ & $158(96.9)$ & \\
\hline \multicolumn{4}{|l|}{ Gender, number (\%) } \\
\hline Women & 147(68.7) & |43(87.7) & $<0.00 I^{* *}$ \\
\hline Men & $67(31.1)$ & $20(12.3)$ & \\
\hline \multicolumn{4}{|c|}{ Education level, number (\%) } \\
\hline Diploma & $16(7.5)$ & 0 & $<0.001 * *$ \\
\hline Associate Degree & $26(12.1)$ & $6(3.7)$ & \\
\hline Bachelor & $87(40.7)$ & $25(15.3)$ & \\
\hline MS & $57(26.6)$ & $61(37.4)$ & \\
\hline Ph.D. & $28(\mid 3 . I)$ & $7 I(43.6)$ & \\
\hline Age, mean \pm SD & $39.04 \pm 13.42$ & $47.93 \pm|2.8|$ & $<0.001 * *$ \\
\hline BMI, mean \pm SD & $28.14 \pm 4.2$ & $29.42 \pm 6.3$ & $0.019 * *$ \\
\hline \multicolumn{4}{|c|}{ Blood Pressure, mean \pm SD } \\
\hline Minimum & $85.17 \pm 11.65$ & $91.28 \pm 9.89$ & $<0.001 * *$ \\
\hline Maximum & $133.32 \pm 18.96$ & $142.03 \pm 27.38$ & $<0.001 * *$ \\
\hline \multicolumn{4}{|c|}{ Metabolic variables, mean \pm SD } \\
\hline Chol & $169.5 \pm 37.56$ & $166.56 \pm 32.52$ & 0.426 \\
\hline TG & $124.13 \pm 7 \mid .60$ & $136.18 \pm 77.80$ & 0.124 \\
\hline HDL_C & $48.77 \pm 12.74$ & $53.26 \pm 16.45$ & $0.004 * *$ \\
\hline LDL_C & $109.5 \pm 33.88$ & $100.74 \pm 33.10$ & $0.012^{* *}$ \\
\hline FBS & $95.36 \pm 10.93$ & $189.94 \pm 64.55$ & $<0.001 * *$ \\
\hline $\mathrm{HbAlc}$ & $5.439 \pm 0.628$ & $8.504 \pm 2.735$ & $<0.001 * *$ \\
\hline
\end{tabular}

Notes: $* * P$-value $<0.05$ is significant.

Abbreviations: LDL-C, low-density lipoprotein cholesterol; HDL-C cholesterol; Chol, High-density lipoprotein cholesterol; HbAIc, Hemoglobin AIc; BMI, Body Mass Index; TG, Triglycerides.

domain score, ${ }^{19}$ the results of the present study are acceptable. The present study showed a significant negative association between $\mathrm{HbA} 1 \mathrm{c}$ and FBS levels on the PCS score. It is similar to the result of Dogan et al, that showed a negative correlation between HbAlc levels and PCS and MCS scores, ${ }^{9}$ but in contrast with the result of Simmons et al, that showed that PCS and MCS were not significantly associated with $\mathrm{HbAlc}$ in multivariable analysis. ${ }^{24}$ The result of a study on diabetic patients with foot ulcers showed that there was a significant negative correlation between fasting blood sugar and quality of life, ${ }^{25}$ and it is similar to the result of the current study.

In investigating the effect of other patients' characteristics such as chronic diseases, age, gender, marital status, social relationships, and level of education on HRQoL among type 2 diabetes patients, many studies have been conducted. ${ }^{26-28}$ The result of this study confirmed that cigarette smoking and lower level of education had a significant negative influence on PCS score. The negative effect of cigarette smoking on HRQoL scores in type 2 diabetes patients has been confirmed. ${ }^{29}$ A study conducted in Turkey proved the negative effect of low educational level on HRQoL scores. ${ }^{27,30}$ According to our knowledge, the effect of educational level on physical activity domains or PCS score has not been conducted. The researchers of the present study are of the opinion that patients with lower levels of education were engaged in jobs that require hard physical activity, and this can lead to worse general health compared to the patients with higher education level. The finding of the present study did not confirm 
Table 2 Comparison between type 2 diabetes and healthy people

\begin{tabular}{|l|l|l|l|}
\hline Domain & Healthy people & Type 2 diabetes & $P$-value \\
\hline PF & $64.03 \pm 27.93$ & $57.99 \pm 28.17$ & $0.039^{*}$ \\
PR & $60.47 \pm 22.39$ & $58.62 \pm 23.02$ & 0.434 \\
RE & $59.56 \pm 21.60$ & $58.53 \pm 21.22$ & 0.643 \\
VT & $44.54 \pm 15.68$ & $42.44 \pm 21.60$ & 0.225 \\
MH & $52.59 \pm 13.23$ & $49.51 \pm 13.66$ & $0.028^{*}$ \\
SF & $57.94 \pm 26.66$ & $54.37 \pm 25.55$ & 0.190 \\
BP & $47.55 \pm 28.14$ & $49.75 \pm 27.41$ & 0.446 \\
GH & $48.32 \pm 19.45$ & $44.05 \pm 16.71$ & $0.02^{*}$ \\
PCS & $67.47 \pm 22.09$ & $61.91 \pm 22.94$ & $0.018^{*}$ \\
MCS & $93.33 \pm 20.02$ & $60.82 \pm 23.52$ & $<0.001 *$ \\
\hline
\end{tabular}

Notes: $* P$-value $<0.05$ is significant.

Abbreviations: PF, physical function; PR, physical role; RE, emotional role; SF, social function; BP, bodily pain; $\mathrm{MH}$, mental health; $\mathrm{VT}$, vitality; $\mathrm{GH}$, general health; MCS, mental component summary; PCS, Physical component summary.

the significant effect of any metabolic variable on the MCS scale score. According to the researchers' knowledge, there is no study that has investigated the effects of metabolic variables on MCS, in addition, studies that explore the effects of these variables on the psychological health of type 2 diabetes patients are rarely found. In the present study, MCS score was influenced positively by smoking, gender, and higher level of education.

As is the case for PCS scale, an increase in the level of education leads to higher MCS score. The present study is in line with another study that showed higher VT and EM domain scores in patients with international education. ${ }^{12}$ Diabetic patients with higher education may have better quality of life due to the fact that they can study more about the symptoms and complications of their disease; thus, they are likely to pay more attention to treatment and diet. $^{31}$ On the other hand, education is a necessary factor in comprehension of self-care management of diabetes and perception of self-esteem. ${ }^{32}$

Table 3 The effects of metabolic variables on two main scales of SF-36 in type 2 diabetes

\begin{tabular}{|c|c|c|c|}
\hline & $\beta$ & 95\% C.I for $\beta$ & $P$-value \\
\hline \multicolumn{4}{|l|}{ PCS score } \\
\hline Cigarette smoking & $-|5.76|$ & $(-16.06,-19.42)$ & 0.009 \\
\hline Drug use & -12.636 & $(-14.26,-9.06)$ & 0.542 \\
\hline \multicolumn{4}{|l|}{ Gender } \\
\hline Men & -3.315 & $(-15.682,9.21)$ & 0.592 \\
\hline Women & Ref & & \\
\hline \multicolumn{4}{|l|}{ Education } \\
\hline Diploma & -10.328 & $(-14.49,-6.32)$ & 0.046 \\
\hline Bachelor & -5.041 & $(-7.92,3.91)$ & 0.597 \\
\hline MS & -3.541 & $(-7.01,1.05)$ & 0.359 \\
\hline Ph.D. & Ref & & \\
\hline Age & -0.011 & $(-0.25,0.29)$ & 0.950 \\
\hline BMI & -0.287 & $(-2.06,-0.17)$ & 0.034 \\
\hline \multicolumn{4}{|l|}{ Blood Pressure } \\
\hline Minimum & -0.039 & $(-0.04,-0.08)$ & 0.009 \\
\hline Maximum & -0.108 & $(-0.068,-0.17)$ & 0.008 \\
\hline \multicolumn{4}{|l|}{ Metabolic variables } \\
\hline Chol & -0.648 & $(-0.73,-0.39)$ & 0.006 \\
\hline TG & -0.116 & $(-0.16,0.13)$ & 0.096 \\
\hline HDL-C & 0.867 & $(-0.99,2.36)$ & 0.058 \\
\hline LDL-C & -0.721 & $(-2.19,-0.69)$ & 0.008 \\
\hline FBS & -0.769 & $(-1.33,-0.56)$ & 0.006 \\
\hline $\mathrm{HbAlc}$ & -0.878 & $(-1.27,-0.41)$ & 0.004 \\
\hline \multicolumn{4}{|l|}{ MCS score } \\
\hline Cigarette smoking & 13.032 & $(10.98,15.19)$ & 0.041 \\
\hline Drug use & 26.78 & $(23.41,29.19)$ & 0.631 \\
\hline
\end{tabular}


Table 3 (Continued).

\begin{tabular}{|c|c|c|c|}
\hline & $\boldsymbol{\beta}$ & 95\% C.I for $\beta$ & $P$-value \\
\hline \multicolumn{4}{|l|}{ Gender } \\
\hline Men & 15.633 & $(12.81,19.55)$ & 0.018 \\
\hline Women & Ref & & \\
\hline \multicolumn{4}{|l|}{ Education } \\
\hline Diploma & $-|3.16|$ & $(-17.58,-10.72)$ & 0.027 \\
\hline Bachelor & -9.57 & $(-11.15,-8.04)$ & $<0.001$ \\
\hline MS & -1.69 & $(-6.19,-0.55)$ & 0.045 \\
\hline Ph.D. & Ref & & \\
\hline Age & -0.076 & $(-0.36,0.21)$ & 0.598 \\
\hline BMI & -0.088 & $(-3.89 ;-0.025)$ & 0.048 \\
\hline \multicolumn{4}{|c|}{ Blood Pressure } \\
\hline Minimum & -0.017 & $(-0.08,0.03)$ & 0.419 \\
\hline Maximum & -0.09 & $(-0.20,0.09)$ & 0.221 \\
\hline \multicolumn{4}{|c|}{ Metabolic variables } \\
\hline Chol & 0.108 & $(-4.09,1.11)$ & 0.637 \\
\hline TG & -0.031 & $(-7.15,2.09)$ & 0.765 \\
\hline HDL-C & -0.291 & $(-2.59,3.14)$ & 0.399 \\
\hline LDL-C & -0.192 & $(-3.20,4.26)$ & 0.402 \\
\hline FBS & 0.063 & $(-3.98,1.91)$ & 0.407 \\
\hline $\mathrm{HbAlc}$ & 0.084 & $(-2.02,1.85)$ & 0.387 \\
\hline
\end{tabular}

Abbreviations: LDL-C, low-density lipoprotein cholesterol; HDL-C cholesterol; Chol, High-density lipoprotein cholesterol; HbAIc, Hemoglobin Alc; BMI, Body Mass Index; FBS, Fasting blood suger; TG, Triglycerides; MCS, mental component summary; PCS, Physical component summary; Ref, Reference category.

BMI had a negative influence on both PCS and MSC scores, and that is in line with Kalda et $\mathrm{al},{ }^{33}$ who used logistic regression analysis, and showed that BMI had a negative effect on the quality of life of diabetic patients. A review by Kushner et al, ${ }^{34}$ that focused on the relation between obesity and quality of life, found that obesity has negative effects on both physical and mental aspects of HRQoL. It is worth mentioning that Sepúlveda et $\mathrm{al}^{34}$ indicated that overweight diabetic patients had lower score in PF and VT domains than the ones with normal weight.

In the present study, gender (men rather than women) had a significant positive effect on MCS scale, ie, Iranian diabetic women had lower MCS score compared to men. This result is not in accordance with the results of Dogan et al, that showed significant differences in PCS scores between women and men, however no significant difference in MCS scores. ${ }^{9}$ Age had no significant effect on the PCS and MCS scores in patients with diabetes in this study, but the consensus of the studies is that quality of life has a negative relationship with age. ${ }^{32}$

It is obvious that patients with diabetes in this study had lower scores in PCS and MCS scale than healthy people.
This result is similar to other studies. ${ }^{35}$ The comparison between patients and healthy people based on domain scores showed that MH, PF, and GH domains had significantly lower scores. The present study is the first one that has used multivariate regression in order to establish the effect of metabolic variables on PSC and MSC scores simultaneously.

\section{Conclusion}

The effect of HRQoL (as a concept of health) on patients with type 2 diabetes could be improved by controlling the variation of some metabolic variables. The results of this study can help physicians improve the HRQoL of patients with type 2 diabetes, based on some metabolic variables which are reported in their routine blood tests.

\section{Acknowledgment}

The authors are grateful to the Besat clinic personnel for their friendly cooperation.

\section{Disclosure}

The authors report no conflicts of interest in this work. 


\section{References}

1. Goldney RD, Phillips PJ, Fisher LJ, Wilson DH. Diabetes, depression, and quality of life: a population study. Diabetes Care. 2004;27 (5):1066-1070. doi:10.2337/diacare.27.5.1066

2. Alberti KGMM, Zimmet P, Shaw J. International diabetes federation: a consensus on type 2 diabetes prevention. Diabetic Med. 2007;24 (5):451-463. doi:10.1111/j.1464-5491.2007.02157.x

3. Whiting DR, Guariguata L, Weil C, Shaw J. IDF diabetes atlas: global estimates of the prevalence of diabetes for 2011 and 2030 Diabetes Res Clin Pract. 2011;94(3):311-321. doi:10.1016/j. diabres.2011.10.029

4. Azimi-Nezhad M, Ghayour-Mobarhan M, Parizadeh M, et al. Prevalence of type 2 diabetes mellitus in Iran and its relationship with gender, urbanisation, education, marital status and occupation. Singapore Med J. 2008;49(7):571.

5. Sweileh WM, Abu-Hadeed HM, Al-Jabi SW, Zyoud HZ. Prevalence of depression among people with type 2 diabetes mellitus: a cross sectional study in Palestine. BMC Public Health. 2014;14(1):163. doi:10.1186/1471-2458-14-163

6. Goodridge D, Trepman E, Embil JM. Health-related quality of life in diabetic patients with foot ulcers: literature review. $J$ Wound Ostomy Continence Nurs. 2005;32(6):368-377. doi:10.1097/00152192200511000-00007

7. Nerenz DR, Repasky DP, Whitehouse FW, Kahkonen DM. Ongoing assessment of health status in patients with diabetes mellitus. Med Care. 1992;MS112-MS124.

8. Grad FP. The preamble of the constitution of the World Health Organization. Bull World Health Organ. 2002;80:981.

9. Dogan H, Harman E, Kocoglu H, Sargin G. Can metabolic control variables of diabetic patients predict their quality of life? J Am Soc Hypertens. 2016;10(1):81-88. doi:10.1016/j.jash.2015.11.014

10. Ciechanowski PS, Katon WJ, Russo JE. Depression and diabetes: impact of depressive symptoms on adherence, function, and costs. Arch Intern Med. 2000;160(21):3278-3285.

11. De Groot M, Anderson R, Freedland KE, Clouse RE, Lustman PJ. Association of depression and diabetes complications: a meta-analysis. Psychosom Med. 2001;63(4):619-630.

12. Cheah W, Lee P, Lim P, Nabila AF, Luk K, Iwana AN. Perception of quality of life among people with diabetes. Malaysian Family Physician. 2012;7(2-3):21.

13. Grandy S, Chapman R, Fox K, Group SS. Quality of life and depression of people living with type 2 diabetes mellitus and those at low and high risk for type 2 diabetes: findings from the study to help improve early evaluation and management of risk factors leading to diabetes (SHIELD). Int J Clin Pract. 2008;62(4):562-568. doi:10.1111/j.1742-1241.2008.01703.x

14. Watkins K, Connell CM. Measurement of health-related QOL in diabetes mellitus. Pharmacoeconomics. 2004;22(17):1109-1126. doi:10.2165/00019053-200422170-00002

15. Imayama I, Plotnikoff RC, Courneya KS, Johnson JA. Determinants of quality of life in adults with type 1 and type 2 diabetes. Health Qual Life Outcomes. 2011;9(1):115. doi:10.1186/1477-7525-9-40

16. Sundaram M, Kavookjian J, Patrick JH, Miller L-A, Madhavan SS, Scott VG. Quality of life, health status and clinical outcomes in Type 2 diabetes patients. Qual Life Res. 2007;16(2):165-177. doi:10.1007/ s11136-006-9105-0

17. McCollum M, Hansen LB, Ghushchyan V, Sullivan PW. Inconsistent health perceptions for US women and men with diabetes. J Women's Health. 2007;16(10):1421-1428. doi:10.1089/jwh.2006.0251
18. Rejeski WJ, Lang W, Neiberg RH, et al. Correlates of health-related quality of life in overweight and obese adults with type 2 diabetes. Obesity. 2006;14(5):870-883. doi:10.1038/oby.2006.101

19. Papadopoulos AA, Kontodimopoulos N, Frydas A, Ikonomakis E, Niakas D. Predictors of health-related quality of life in type II diabetic patients in Greece. BMC Public Health. 2007;7(1):186. doi:10.1186/1471-2458-7-186

20. Saito I, Inami F, Ikebe T, et al. Impact of diabetes on health-related quality of life in a population study in Japan. Diabetes Res Clin Pract. 2006;73(1):51-57. doi:10.1016/j.diabres.2005.11.015

21. Montazeri A, Goshtasebi A, Vahdaninia M, Gandek B. The short form health survey (SF-36): translation and validation study of the Iranian version. Qual Life Res. 2005;14(3):875-882.

22. Ware JE, Kosinski M, Dewey JE. How to Score Version 2 of the SF36 Health Survey (standard \& Acute Forms). QualityMetric Incorporated; 2000.

23. Kiadaliri AA, Najafi B, Mirmalek-Sani M. Quality of life in people with diabetes: a systematic review of studies in Iran. $J$ Diabetes Metab Disord. 2013;12(1):54. doi:10.1186/2251-6581-12-54

24. Kuznetsov L, Griffin SJ, Davies MJ, et al. Diabetes-specific quality of life but not health status is independently associated with glycaemic control among patients with type 2 diabetes: a cross-sectional analysis of the ADDITION-Europe trial cohort. Diabetes Res Clin Pract. 2014;104(2):281-287. doi:10.1016/j.diabres.2013.12.029

25. Navicharern R. Diabetes self-management, fasting blood sugar and quality of life among type 2 diabetic patients with foot ulcers. $J$ Med Assoc Thailand. 2012;95(2):156-162.

26. Rubin RR, Peyrot M. Quality of life and diabetes. Diabetes Metab Res Rev. 1999;15(3):205-218.

27. Akinci F, Yildirim A, Gözü H, Sargın H, Orbay E, Sargın M. Assessment of health-related quality of life (HRQoL) of patients with type 2 diabetes in Turkey. Diabetes Res Clin Pract. 2008;79 (1):117-123. doi:10.1016/j.diabres.2007.07.003

28. Williams GC, Zeldman A. Patient-centered diabetes self-management education. Curr Diab Rep. 2002;2(2):145-152.

29. Strandberg AY, Strandberg TE, Pitkälä K, Salomaa VV, Tilvis RS, Miettinen TA. The effect of smoking in midlife on health-related quality of life in old age: a 26-year prospective study. Arch Intern Med. 2008;168(18):1968-1974. doi:10.1001/archinte.168.18.1968

30. Quah JH, Luo N, Ng WY, How CH, Tay EG. Health-related quality of life is associated with diabetic complications, but not with shortterm diabetic control in primary care. Ann Acad Med Singapore. 2011;40(6):276.

31. Issa B, Baiyewu O. Quality of life of patients with diabetes mellitus in a Nigerian teaching hospital. Hong Kong $J$ Psychiatry. 2006;16 (1):27-34.

32. Nyanzi R, Wamala R, Atuhaire LK. Diabetes and quality of life: a Ugandan perspective. J Diabetes Res. 2014;2014.

33. Kalda R, Rätsep A, Lember M. Predictors of quality of life of patients with type 2 diabetes. Patient Prefer Adherence. 2008;2:21.

34. Sepulveda E, Poinhos R, Constante M, Pais-Ribeiro J, Freitas P, Carvalho D. Health-related quality of life in type 1 and type 2 diabetic patients in a Portuguese central public hospital. Diabetes Metab Syndrome Obesity. 2015;8:219. doi:10.2147/DMSO.S80472

35. Tapp RJ, Dunstan DW, Phillips P, et al. Association between impaired glucose metabolism and quality of life: results from the Australian diabetes obesity and lifestyle study. Diabetes Res Clin Pract. 2006;74(2):154-161. doi:10.1016/j.diabres.2006.03.012 


\section{Publish your work in this journal}

Diabetes, Metabolic Syndrome and Obesity: Targets and Therapy is an international, peer-reviewed open-access journal committed to the rapid publication of the latest laboratory and clinical findings in the fields of diabetes, metabolic syndrome and obesity research. Original research, review, case reports, hypothesis formation, expert opinion and commentaries are all considered for publication. The manuscript management system is completely online and includes a very quick and fair peer-review system, which is all easy to use. Visit http://www.dovepress.com/testimonials.php to read real quotes from published authors.

Submit your manuscript here: https://www.dovepress.com/diabetes-metabolic-syndrome-and-obesity-targets-and-therapy-journal 